\title{
El papel de los pieds-noirs en la economía alicantina entre finales de los años 50 y los años 70
}

\section{The role of the pieds-noirs in the economy of Alicante between the late 1950s and the 1970s}

\author{
Mariana Domínguez Villaverde \\ Université Grenoble-Alpes \\ Mariana.Dominguez-Villaverde@univ-grenoble-alpes.fr \\ http://orcid.org/0000-0002-8342-0646
}

Recibido: 15/09/2021

Aceptado: 22/11/2021

Cómo citar este artículo: DOMíNGUEZ VILLAVERDE, Mariana (2022). El papel de los pieds-noirs en la economía alicantina entre finales de los años 50 y los años 70 . Pasado y Memoria. Revista de Historia Contemporánea, (24), pp. 295-321, https:// doi.org/10.14198/PASADO2022.24.12

\section{Resumen}

Los europeos procedentes de Argelia instalados en Alicante desde 1962 contribuyeron ampliamente al desarrollo de la provincia y al impulso del sector terciario. El presente estudio propone un análisis espacial de la instalación de los denominados pieds-noirs en Alicante. Para ello, se identifican las actividades económicas que esas personas llevaron a cabo y su evolución en el tiempo, vinculada a la propia evolución social, económica y urbanística que atravesó la provincia de Alicante y su capital desde finales de los años 50. El análisis de las actividades económicas pieds-noirs, se inserta en un estudio más amplio sobre las transformaciones urbanas y económicas de Alicante, en un contexto de cambios sociales.

Palabras clave: Pieds-Noirs; Alicante; Actividades económicas; Sector terciario; Turismo; Transformación urbana. 


\begin{abstract}
The Europeans from Algeria who settled in Alicante since 1962 extensively contributed to the development both of the province and the tertiary sector. This paper proposes a spatial analysis of the so-called pied-noir settelmemt in Alicante by identifying the economic activities those people carried out and their further evolution, linked to the social, economic, and urban progress that both the province of Alicante and its capital underwent since the end of the 1950s. The analysis of the pieds-noirs economic activities is part of a broader study of the urban and economic transformations of Alicante, in the context of social changes.
\end{abstract}

Keywords: Pieds-Noirs; Alicante; Economic Activities; Tertiary Sector; Tourism; Urban Transformation.

En torno a 1962 varias decenas de miles de pieds-noirs ${ }^{1}$ se instalaron en la provincia de Alicante como resultado de la independencia de Argelia. La implantación de este grupo en el litoral alicantino dio lugar a un mito sobre su impacto económico y social, que habría sido extraordinario. La historiografía ha señalado la contribución de la comunidad pied-noir al desarrollo de la provincia y al impulso del sector terciario (Seva, 1968; Palacios, 1968, Sempere, 1998-2001) ${ }^{2}$. Sin embargo, ningún trabajo de investigación había descrito en detalle ese proceso.

Este estudio ${ }^{3}$ se propone cubrir esa laguna y cuestionar la autenticidad del «mito pied-noir», en particular a partir del análisis de fuentes locales y provinciales.

Nuestro primer objetivo será identificar las actividades económicas que llevaron a cabo los pieds-noirs de Alicante ${ }^{4}$ y su evolución en el tiempo. En segundo lugar, proponemos insertar el análisis de las actividades económicas pieds-noirs en un estudio más amplio sobre las transformaciones urbanas y económicas que atravesaron la provincia de Alicante y su capital desde finales de los años $50^{5}$.

1. Se llamó así a los europeos de Argelia que debieron abandonar la colonia francesa como resultado de la descolonización en 1962.

2. Sempere propuso la primera aproximación rigurosa al perfil socio-profesional de los repatriados del Norte de África en Alicante, en la que se apoya nuestro trabajo.

3. Se inscribe en el marco de la tesis doctoral Ser y Estar. Los Pieds-Noirs d'Alicante et de sa région d'une rive à l'autre de la Méditerranée (1962-années 2000) de la autora.

4. Cuando nos refiramos a Alicante sin añadir ninguna precisión estaremos hablando de la provincia.

5. Algunos estudios señalan la presencia de pieds-noirs, aunque más escasa, en otras zonas de España. Cabe destacar el caso de las Islas Baleares y Cataluña, donde los europeos de 


\section{Delimitación de nuestro objeto de estudio y metodología}

Nuestra definición de los pieds-noirs ${ }^{6}$ como objeto de estudio se aleja de las definiciones basadas en la nacionalidad o el lugar de nacimiento y tiene en cuenta aspectos identitarios y culturales que nos parecen imprescindibles para definir a esta población exiliada. En nuestro análisis hemos decidido incluir a todas aquellas personas que, según los datos del padrón u otras fuentes, pudieran ser consideradas como pieds-noirs. En primer lugar, hemos incluido a europeos nacidos en Argelia o que habían pasado una parte de su vida en la antigua colonia francesa, llegados a Alicante entre los años 50 y 70 . Muchos de ellos poseían la nacionalidad francesa, otros seguían siendo españoles. En segundo lugar, hemos contabilizado a las personas que habían residido durante un tiempo en Argelia y regresado a Alicante (generalmente su región de origen) durante la Guerra de independencia argelina. En ambos casos, hemos incluido a sus familias. Por último, hemos tenido en cuenta a personas que formaron parte de la red de influencia y sociabilidad pied-noir, aunque no sepamos con certeza si se trata de pieds-noirs, franceses u otros repatriados. Este último grupo, formado por personas que participaron activamente en las actividades económicas de la época, nos permitirá estudiar el fenómeno pied-noir en conexión con la sociedad de acogida y con la colonia francesa que existía en Alicante antes de 1962 y que se reforzó con la llegada de nuevos residentes en los años 60 y 70 . Hemos llamado a esos diferentes grupos Tipo 1, 2 y 3 respectivamente.

\begin{tabular}{|l|c|}
\hline \multicolumn{1}{|c|}{ Tipo de perfil } & Identification \\
\hline Pieds-noirs o españoles «retornados» & T1-T2 \\
\hline Originarios del Marruecos francés & T3a \\
\hline $\begin{array}{l}\text { Probablemente pieds-noirs o franceses con lazos } \\
\text { estrechos con la comunidad. }\end{array}$ & T3b \\
\hline Relación estrecha con el mundo pied-noir. & T3c \\
\hline $\begin{array}{l}\text { Casi con certeza pieds-noirs (por el nombre, las redes, } \\
\text { las actividades, la familia) }\end{array}$ & T3 d \\
\hline
\end{tabular}

Tabla n. ${ }^{\circ}$ 1: Clasificación de la población estudiada.

Una vez definidos nuestro objeto y nuestra perspectiva, hemos procedido a localizar a los pieds-noirs de Alicante, sus actividades económicas y culturales,

Argelia parecen haber contribuido también al desarrollo económico y urbanístico, como lo indican los trabajos de Marimon Riutort (2013).

6. Las autoridades, la prensa y la sociedad alicantinas se refirieron a ellos de esta manera, pero también como pies negros, refugiados de Argelia o argelinos. 
sus lugares de residencia y trabajo en diversos archivos. En primer lugar, hemos analizado los padrones de habitantes de la ciudad de Alicante y de otras ciudades de la provincia. En los fondos españoles y alicantinos, así como en la prensa, para estudiar a esta población hemos tenido que realizar un trabajo de búsqueda exhaustivo y minucioso reconstruyendo el puzzle de su presencia dispersa. En efecto, hemos consultado diversos fondos de los archivos municipales de Alicante (AMA), de Jávea, de El Campello, de Villajoyosa, de San Vicente del Raspeig y de Benidorm (en particular licencias de apertura, rentas de comercios). También hemos trabajado a partir de la documentación conservada en el Archivo histórico provincial (fondos Gobierno civil y DIT), en el Centro de Archivos diplomáticos de Nantes (CADN-AMAE), donde tuvimos acceso a los fondos de los consulados franceses de Valencia y Alicante, y en el Archivo de la Universidad de Alicante (Fondos Pedro Zaragoza Orts), y de varias serie de colecciones de prensa (particularmente la publicación Le Courrier du Soleil ${ }^{7}$ ). Por último, hemos realizado una serie de entrevistas.

A partir de la documentación, hemos elaborado una serie de bases de datos, que hemos analizado cuantitativamente. Ese estudio nos ha permitido identificar los lugares de residencia de los pieds-noirs en la ciudad y en la región, y repertoriar y localizar geográficamente los negocios y actividades económicas pertenecientes a alguna de las categorías señaladas (Tipo 1,2,3).

\section{La implantación de los pieds-noirs en la provincia de Alicante}

La llegada de los pieds-noirs a Alicante se produjo en forma de varias oleadas comprendidas entre finales de los años 50 y los años 70. En el año 1962, particularmente en los meses de verano, se produjo el mayor número de entradas. Si bien los «30.000 pieds-noirs» evocados por la historiografía y la prensa durante años no han podido ser localizados, se trata de una cifra plausible si nos referimos a personas de todas las nacionalidades, instalados en toda la provincia de Alicante y llegados en diferentes momentos.

Como lo han mostrado los estudios al respecto ${ }^{9}$, la presencia pied-noir en la ciudad de Alicante fue especialmente numerosa en los barrios del centro y en los barrios semiperiféricos y periféricos del norte de la ciudad. Por otro lado,

7. Semanario pied-noir publicado en Alicante entre 1965 y 1967.

8. Se trata de 56 entrevistas a pieds-noirs o a personas relacionadas que han vivido o tienen algún vínculo con la provincia de Alicante. Algunas de ellas fueron en profundidad, otras fueron conversaciones más breves o telefónicas.

9. El análisis de los lugares de residencia de los migrantes de las descolonizaciones del Norte de África ya había sido realizado por Sempere a partir del padrón de 1965. Nuestro trabajo estudia la evolución entre 1965 y 1970 y se centra en las actividades económicas. 
muchos pieds-noirs y franceses se instalaron en zonas modernas y dinámicas, generalmente cercanas a la costa, como Muchavista, La Albufereta, Raval Roig o Playa San Juan. A nivel provincial, los pueblos de origen de muchos pieds-noirs (La Nucia, Polop) y las ciudades costeras (Benidorm, Santa Pola, Torrevieja) parecen haber atraído un gran número de exiliados de Argelia. La ocupación espacial de los pieds-noirs en la ciudad y la provincia de Alicante fue evolucionando desde finales de los años 50 hasta los años 70, gracias a las nuevas llegadas, la integración económica de las familias y la evolución económica y urbanística de la región, a la que ellos contribuyeron ampliamente.

Debemos precisar que una parte de los pieds-noirs llegados a Alicante antes de 1962, había huido de Argelia con pequeñas fortunas ${ }^{10} \mathrm{o}$ había invertido en la región (en negocios y apartamentos) antes de instalarse. La mayoría de los pieds-noirs, sin embargo, atravesaron grandes dificultades económicas durante los primeros años de vida en Alicante y tuvieron que endeudarse para poder financiar sus emprendimientos. Eso fue posible gracias a la acogida positiva que las autoridades locales y la sociedad les ofrecieron. Su potencial como inversores, su perfil socioeconómico ${ }^{11}$ y el hecho de que vinieran de un país más avanzado y con un savoir-faire particular fueron las principales razones de esta acogida y motivaron las ayudas que les fueron otorgadas (créditos, facilidades administrativas) ${ }^{12}$. En efecto, los pieds-noirs encontraron en Alicante un terreno favorable a su instalación, tanto del punto de vista de la recepción local, como del contexto económico. En los años 60, la región de Alicante iniciaba su espectacular despegue y necesitaba inversiones e iniciativas.

Los pieds-noirs llegaron a España en pleno inicio del desarrollismo. La modernización económica y el desarrollo de la sociedad de consumo fueron particularmente importantes en una provincia como Alicante, marcada por el auge de la actividad turística y el crecimiento exponencial del sector terciario (Moreno Sáez; Martínez Leal, 2018).

Los europeos de Argelia se inscribieron plenamente en las tendencias de desarrollo que se delineaban desde los años 50 y estimularon el crecimiento de ciertos sectores que respondían a nuevas necesidades generadas por el aumento

10. En algunos casos eran sólo ahorros modestos, pero que en el Alicante de la época tenían más valor.

11. En general, familias de clase media y trabajadores del sector terciario.

12. Además de estas razones, debemos señalar motivos políticos, ya que los pieds-noirs, por sus posturas conservadoras en Argelia, fueron vistos por el Régimen franquista como aliados. Las autoridades locales, que los recibieron con los brazos abiertos, pidieron en varias ocasiones a la comunidad que se manifestara a favor del franquismo. Algunos de sus miembros lo hicieron, por ejemplo, en 1966, cuando participaron en las manifestaciones a favor del «Sí» a la Ley orgánica, y en 1970, en el marco de los procesos de Burgos. 
de la población y del nivel de vida y por la evolución de las modalidades de consumo.

La instalación en Alicante tuvo como particularidad la concentración en un espacio relativamente reducido, lo que favoreció cierta cohesión de grupo y produjo una impresión de «invasión $»^{13}$. Los comercios pieds-noirs fueron visibles por su originalidad o exotismo, esencialmente en ciertas zonas de la ciudad. La primera de ellas, en pleno centro histórico de la ciudad, fue la Rambla Méndez Núñez, centro neurálgico y burgués de la ciudad desde el siglo XIX. Ésta albergó una multiplicidad de actividades comerciales pieds-noirs, especialmente en dos de sus construcciones modernas en altura, La Torre Provincial en el número $45 \mathrm{y}$ el Edificio Secades en el 66. Los negocios piedsnoirs se transformaron en referentes de la expansión urbana y del cambio en los modos de vida. Podemos pensar en la sala de fiestas Pigalle, situada en la terraza de la Torre Provincial y cuyo rótulo estuvo asociado durante mucho tiempo a la imagen de La Rambla. La segunda zona en la que la presencia pied-noir fue particularmente visible fue La Explanada, paseo marítimo que sufrió una importante transformación en los años 60. Esta gran arteria de la ciudad fue ocupada desde finales de los años 50 por grandes cafeterías con terrazas, toldos a la francesa y decoraciones inéditas, por bares y cafeterías con nombres extranjeros, como los snacks, whiskies, milkbars y boîtes. Otras zonas de la ciudad recibieron un aflujo igual o mayor de comercios pied-noir, aunque éstos tuvieron menos notoriedad en la memoria alicantina. Numerosos establecimientos situados en barrios como El Pla o Carolinas, vendían productos típicos franceses o de Argelia y fueron lugares de encuentro o de autoayuda espontáneos para los miembros de la comunidad. Si nos alejamos del centro de la ciudad de Alicante, otro espacio emblemático de la instalación pied-noir fue La Albufereta. Ese complejo urbano edificado por Carlos Pradel, personalidad cercana a los pieds-noirs de Alicante ${ }^{14}$, fue el lugar de residencia de muchos europeos de Argelia y franceses, sobre todo desde mediados de los años 60. La presencia de los europeos de Argelia en ciertas zonas hasta entonces prácticamente vírgenes contribuyó a reforzar la idea de «invasión», sobre todo en barrios como La Albufereta y o zonas como Playa San Juan y, en particular, Cabo de Huertas. En esta zona recientemente urbanizada algunos europeos de Argelia solían pasar sus vacaciones antes de 1962 y poseían apartamentos. Junto con el aumento del número de residentes pieds-noirs y franceses se produjo la

13. Como lo señalaban la prensa de la época y los testimonios de los alicantinos.

14. Carlos Pradel fue un empresario y promotor inmobiliario alicantino de origen suizo. Fue uno de los principales inversores de la Nouvelle Ecole Française (NEF), creada por los pieds-noirs en 1962, y la dirigió desde mediados de los años 60. 
multiplicación de comercios y empresas gestionados por ellos. Finalmente, otros barrios cercanos a la costa, como Vistahermosa, La Goteta y Raval Roig (especialmente la calle Virgen del Socorro), vieron florecer establecimientos pieds-noirs.

En los años 60 y 70 se instalaron en estas zonas el Consulado francés, varias asociaciones francesas y pieds-noirs y la Nouvelle Ecole Française (actual Liceo Francés de Alicante), otros signos de la presencia de los europeos de Argelia.

\section{El perfil profesional de los pieds-noirs de Alicante}

El trabajo sobre el padrón de habitantes de 1965 de la ciudad de Alicante nos ha permitido identificar 1245 personas que podríamos considerar como pieds-noirs (Tipo 1-2) ${ }^{15}$ y observar su influencia en determinados sectores de la economía. Entre ellos, el $73,2 \%$ corresponde a la población no activa y el $26,8 \%$ a la población activa. Las principales actividades de los activos eran el comercio, los oficios y la pequeña industria. Entre los que trabajan en el comercio, como empleados o propietarios, 22 personas ( $6,6 \%$ de la población activa) lo hacen en los sectores de la moda, la belleza, la estética o el lujo. Hemos localizado 33 personas ( $10 \%$ de la población activa) que trabajan como empleados o propietarios de comercios de alimentación, de ocio o de artículos para hogar (decoración, muebles, electrodomésticos). En el primer caso, 13 son panaderos y/o pasteleros; 9 poseen un supermercado o un comercio de venta de alimentación o trabajan en él, 11 son empleados o propietarios de un bar, un restaurante, una cafetería; 1 es carnicero. 73 personas (21\% de la población activa) se presentan como propietarios o empleados de otro tipo de comercio o industria no especificado.

El padrón de habitantes de Alicante de 1970 nos permite observar la evolución de las familias que permanecieron en la región en periodo intercensal, así como las tendencias que siguen los miembros de las nuevas oleadas ${ }^{16}$. La siguiente tabla describe la comparación entre los llegados antes de 1965 y que permanecen en 1970, los llegados antes de 1965 y que ya no residen en la capital de la provincia en 1970, los que viven en ella en ambos periodos y las personas que aparecen por primera vez en el padrón de 1970 (llegadas antes de 1965 y no inscritas o llegadas después de 1965).

15. Nuestras cifras difieren de las propuestas por Sempere para 1965 porque hemos definido nuestro objeto de estudio de manera diferente. Pero globalmente, nuestras conclusiones son similares.

16. Desde esa fecha llegan en su mayoría desde Francia, por lo que tienen otro perfil. 


\begin{tabular}{|c|c|c|c|c|c|}
\hline & \multirow[b]{2}{*}{1965} & \multirow[b]{2}{*}{1970} & \multirow{2}{*}{$\begin{array}{c}\text { Ya no están en } \\
1970\end{array}$} & \multicolumn{2}{|c|}{ Nuevos en 1970} \\
\hline & & & & Antes 1965 & $\begin{array}{c}\text { Después } \\
1965\end{array}$ \\
\hline Total personas & 1245 & 1869 & 589 & 483 & 662 \\
\hline $\begin{array}{l}\text { Jubilados y } \\
\text { pensionistas }\end{array}$ & $10,52 \% *(131)$ & $11,66 \%(218)$ & $10,86 \%(64)$ & $9,52 \%(46)$ & $14,65 \%(97)$ \\
\hline Rentistas & $1,36 \%(17)$ & $0,1 \%(2)$ & $1,18 \%(7)$ & $0 \%(0)$ & $0,3 \%(2)$ \\
\hline Amas de casa & $32,85 \%(409)$ & $24,98 \%(467)$ & $31,4 \%(185)$ & $24 \%(116)$ & $21,9 \%(145)$ \\
\hline $\begin{array}{l}\text { Escolares y } \\
\text { Estudiantes }\end{array}$ & $18,55 \%(231)$ & $20,06 \%(375)$ & $17,82 \%(105)$ & $17,18 \%(83)$ & $21,45 \%(142)$ \\
\hline Incapacitados & $0,32 \%(4)$ & $0,32 \%(6)$ & $0,5 \%(3)$ & $0,41 \%(2)$ & $0,45 \%(3)$ \\
\hline $\begin{array}{l}\text { Menores no } \\
\text { escolarizados }\end{array}$ & $5,6 \%(70)$ & $5,51 \%(103)$ & $8,65 \%(51)$ & $0,41 \%(2)$ & $8,76 \%(58)$ \\
\hline No declaran & $4 \%(50)$ & $10,59 \%(198)$ & $3,56 \%(21)$ & $16,14 \%(78)$ & $11,17 \%(74)$ \\
\hline Población active & $26,8 \%(333$ & $26,75 \%(500)$ & $26 \%(153)$ & $32,3 \%(156)$ & $21,3 \%(141)$ \\
\hline $\begin{array}{l}\text { Agricultura y } \\
\text { ganadería }\end{array}$ & $4,8 \% *(16)$ & $2,2 \%(11)$ & $6,53 \%(10)$ & $1,28 \%(2)$ & $2,83 \%(4)$ \\
\hline Pesca & $0,6 \%(2)$ & $0,2 \%(1)$ & $0,65 \%(1)$ & $0 \%(0)$ & $0 \%(0)$ \\
\hline $\begin{array}{l}\text { Oficios, } \\
\text { Artesanos }\end{array}$ & $19.21 \%(64)$ & $16,4 \%(82)$ & $22,87 \%(35)$ & $15,38 \%(24)$ & $20,56 \%(29)$ \\
\hline Obreros & $0,9 \%(3)$ & $2,8 \%(14)$ & $1,3 \%(2)$ & $3,84 \%(6)$ & $3,54 \%(5)$ \\
\hline $\begin{array}{l}\text { Empleados } \\
\text { público/privado }\end{array}$ & $9,3 \%(31)$ & $19,6 \%(98)$ & $13 \%(20)$ & $21,79 \%(34)$ & $17,02 \%(24)$ \\
\hline $\begin{array}{l}\text { Directivos } \\
\text { público/privado }\end{array}$ & $1,5 \%(5)$ & $1,2 \%(6)$ & $1,9 \%(3)$ & $1,92 \%(3)$ & $1,41 \%(2)$ \\
\hline $\begin{array}{l}\text { Inmobiliaria/ } \\
\text { seguros }\end{array}$ & $1,8 \%(6)$ & $2,6 \%(13)$ & $1,3 \%(2)$ & $2,56 \%(4)$ & $0,7 \%(1)$ \\
\hline $\begin{array}{l}\text { Transporte e } \\
\text { import-export }\end{array}$ & $1,8 \%(6)$ & $1,2 \%(6)$ & $0,65 \%(1)$ & $0 \%(0)$ & $1,41 \%(2)$ \\
\hline $\begin{array}{l}\text { Comercio moda } \\
\text { y estética }\end{array}$ & $6,6 \%(22)$ & $7 \%(35)$ & $7,84 \%(12)$ & $5,77 \%(9)$ & $4,25 \%(6)$ \\
\hline $\begin{array}{l}\text { Comercio, } \\
\text { alimentación, } \\
\text { hostelería, } \\
\text { hogar, ocio. }\end{array}$ & $10 \%(33)$ & $22,2 \%(111)$ & $9,15 \%(14)$ & $22,43 \%(35)$ & $21,9 \%(31)$ \\
\hline $\begin{array}{l}\text { Comercio e } \\
\text { industria: otros }\end{array}$ & $22,1 \%(73)$ & $11,6 \%(58)$ & $17,64 \%(27)$ & $12,17 \%$ (19) & $12,76 \%(18)$ \\
\hline Arte y deporte & $2,4 \%(8)$ & $0,4 \%(2)$ & $3,26 \%(5)$ & $1,28 \%(2)$ & $0 \%(0)$ \\
\hline $\begin{array}{l}\text { Profesiones } \\
\text { cualificadas: } \\
\text { intelectuales y } \\
\text { técnicas }\end{array}$ & $4,2 \%(14)$ & $4,4 \%(22)$ & $2,61 \%(4)$ & $1,28 \%(2)$ & $6,38 \%(9)$ \\
\hline $\begin{array}{l}\text { Empleados } \\
\text { domésticos }\end{array}$ & $1,2 \%(4)$ & $1 \%(5)$ & $1,96 \%(3)$ & $1,28 \%(2)$ & $0,7 \%(1)$ \\
\hline Sin empleo & $1,8 \%(6)$ & $1,4 \%(7)$ & $0,65 \%(1)$ & $2,56 \%(4)$ & $0,7 \%(1)$ \\
\hline Otros & $12 \%(40)$ & $5,8 \%(29)$ & $8,5 \%(13)$ & $6,41 \%(10)$ & $5,7 \%(8)$ \\
\hline
\end{tabular}

Tabla n. ${ }^{\circ}$ 2: Clasificación de las actividades económicas realizadas por los pieds-noirs de Alicante, según los padrones de habitantes de Alicante de 1965 y 1970. Fuente: AMA. 
Entre las 589 personas que parecen haber abandonado la ciudad o el país antes de 1970, en más de la mitad de los casos se trata de empleados del sector público y privado (administrativos, vendedores, secretarias, empleados, directivos, representantes, etc.). Casi dos tercios de los trabajadores agrícolas, y una cantidad algo inferior a la mitad de los artesanos o personas que ejercían un oficio ya no aparecen inscritos en el padrón de 1970. Sin embargo, entre los comerciantes, parece haber habido una tendencia más acusada a permanecer en la ciudad, con sólo un 41\% de salidas entre los instalados desde 1965 o anteriormente. Esto podría ser un indicador de estabilidad y señalar un mayor éxito en ese dominio. Asimismo, el hecho de ejercer una actividad como autónomo y poseer un local, ha podido reforzar el arraigo al territorio. El estudio de la población pied-noir del padrón de 1970 nos permite reforzar esa hipótesis. Mientras que el porcentaje de personas que realizan distintos oficios se va reduciendo (proporcionalmente, aunque aumente la cantidad total), el de los comerciantes se acrecienta significativamente a pesar de la salida de numerosos comerciantes desde 1965 , pasando de $38,7 \%$ del total (128 personas) a $40,8 \%$ (204) en 1970. El número de empleados en el sector privado y especialmente en el público, sufrió también un fuerte crecimiento.

El recuento de población de 1970 nos muestra que la actividad comercial de los pieds-noirs se caracterizó por un predominio de comercios en relación con la hostelería y la restauración, el ocio, la alimentación, los electrodomésticos y el universo doméstico $(22,2 \%)$.

Podemos afirmar que, entre la población activa, los perfiles dominantes (empleados, comerciantes, artesanos), se mantuvieron a un nivel relativamente estable entre 1965 y 1970. Las salidas parecen haber sido inferiores en el grupo de los comerciantes cuya representación permanece equilibrada en el periodo intercensal. Entre los nuevos llegados después de 1965, constatamos, en efecto, una cantidad superior de comerciantes en relación con las otras profesiones. Hemos aislado del conjunto dos categorías, al no saber si se trataba de empleados o de autónomos: las personas que trabajan en los transportes y la exportación, en número escaso y que parecen reducirse con el tiempo; los agentes de seguros e inmobiliarios, presentes en proporción poco significativa numéricamente, pero cuya importancia en otras fuentes es mayor.

Más allá de esas categorías de empleo predominantes y estables en el tiempo, notamos un aumento de jubilados entre 1965 y 1970, cuyas salidas son compensadas por las nuevas llegadas después de 1965. Esta parte de la población parece haber constituido una proporción importante de las oleadas migratorias tardías. Muchos de ellos habían partido a Francia desde Argelia tras la independencia y decidieron instalarse en España más tarde, tras poner 
en orden su situación administrativa y profesional. Cabe notar asimismo una reducción del porcentaje de amas de casa entre 1965 y 1970. Esto no se explica por las salidas de carácter familiar, ya que sólo un tercio de las amas de casa abandonaron la ciudad entre 1965 y 1970, cantidad inferior a las de los escolares, estudiantes y jubilados que lo hicieron. Podríamos, por lo tanto, explicar esta situación por la inserción laboral de muchas mujeres pieds-noirs que en el recuento de 1965 se declaraban inactivas y por la llegada desde Francia de numerosas parejas en las que la mujer ejercía una actividad. Por otra parte, en 1965 muchas mujeres declaraban ocuparse de «Sus labores» mientras que en 1970 se presentan como parte activa en los negocios familiares, lo que sin duda había sido una realidad desde el primer momento.

La tabla n. ${ }^{\circ} 3$ ilustra la comparación entre la situación profesional del grupo de población que está presente en los padrones de 1965 y de 1970 (656 personas).

\begin{tabular}{|l|c|c|}
\hline & $1965(656)$ & $1970(656)$ \\
\hline Jubilados & $53(8,08 \%) *$ & $67(10,21 \%)$ \\
\hline Etudiantes & $125(19,05 \%)$ & $49(7,47 \%)$ \\
\hline Amas de casa & $222(33,84 \%)$ & $179(27,28 \%)$ \\
\hline Otros inactivos & $14(2,13 \%)$ & $3(0,45 \%)$ \\
\hline No declaran & $51(7,77 \%)$ & $174(26,52 \%)$ \\
\hline Población activa & $191(29,11 \%)$ & $184(28,04 \%)$ \\
\hline Agricultura & $8(4,18 \%) *$ & $6(3,26 \%)$ \\
\hline $\begin{array}{l}\text { Comercio/Empresa/ } \\
\text { Servicios }\end{array}$ & $74(38,7 \%)$ & $100(15,24 \%)$ \\
\hline Empleados & $36(18,84 \%)$ & $33(17,93 \%)$ \\
\hline Oficios / Obreros & $33(17,27 \%)$ & $28(15,21 \%)$ \\
\hline Profesiones cualificadas & $9(4,71 \%)$ & $9(4,89 \%)$ \\
\hline Construcción, inmobiliaria. & $3(1,57 \%)$ & $7(3,8 \%)$ \\
\hline Otros & $28(14,66 \%)$ & $1(0,54 \%)$ \\
\hline
\end{tabular}

Tabla n. ${ }^{\circ}$ 3: Comparación del perfil profesional de las personas presentes en los padrones de 1965 y 1970 (656). Fuente: AMA.

Globalmente, la tasa de actividad de las familias en el periodo intercensal permanece relativamente estable. Las categorías profesionales a las que pertenece este subgrupo presentan un perfil similar al del conjunto (teniendo en cuenta los nuevos llegados desde 1965). La tabla n. ${ }^{\circ} 3$ pone de relieve un 
aumento de la presencia de emprendedores en el sector inmobiliario y de la construcción en 1970.

Frente a esta estabilidad, podemos percibir una serie de evoluciones notables que surgen de un análisis en detalle de los padrones. En primer lugar, la tasa de inactividad, correspondiente esencialmente a rentistas en 1965, se redujo en 1970. Estas personas se declaran en 1970 como activos, jubilados, amas de casa. El número de escolares o estudiantes se redujo también considerablemente entre 1965 y 1970, lo que refleja la inserción profesional o el paso a la categoría de ama de casa de sus efectivos. Es interesante ver cómo evolucionan profesionalmente las nuevas generaciones en relación con sus padres. En efecto, entre los 125 niños y jóvenes escolarizados o estudiantes en 1965, un 32\% (40) continúan sus estudios en 1970, mientras que 37 comienzan a trabajar ${ }^{17}$. En cuanto a los 37 estudiantes que declaran una actividad en 1970, 6 realizan profesiones cualificadas, 10 son empleados en empresas (particularmente en la administración), 12 trabajan en el comercio o la restauración, en algunos casos en la empresa familiar, 1 realiza un oficio, y 8 son amas de casa. Los jóvenes pieds-noirs de Alicante han seguido desde finales de los años 60 caminos profesionales similares a los de sus mayores ${ }^{18}$.

La comparación de ambos padrones nos ofrece datos muy interesantes, pero ambas fuentes tienen sus límites. Por ejemplo, el padrón de 1970 no refleja una presencia numerosa de profesores ni de otras profesiones que se desarrollaron a medida que crecía la colonia instalada en Alicante. No obstante, otras fuentes hacen referencia a una mayor presencia de esos grupos. Su aporte nos permitirá tener en cuenta esas «ausencias» en los padrones y el papel importante que desempeñaron esas profesiones en la estructuración de la comunidad pied-noir de Alicante.

Nuestras bases de datos nos muestran tres tendencias principales: un remplazo progresivo de las actividades manuales por el comercio o a la empresa en el sector terciario, una mejora en el ámbito profesional, y una tímida pero paulatina inserción de las mujeres en el mundo del trabajo. Aunque las actividades profesionales del grupo fueron bastante diversificadas, su participación fue particularmente importante en el comercio, la restauración y la hostelería.

17. El 38,4\% (48 personas) no ha completado esta columna del padrón, por lo que no podemos ir más lejos.

18. Hemos consultado las licencias de apertura hasta el año 1968. Recientemente, hemos podido acceder a los años 1969 y 1970 en el catálogo en línea del AMA (sin poder consultar los expedientes) localizando más de 30 nuevos comercios que siguen las mismas tendencias (zonas, actividad) y refuerzan nuestro estudio sobre la evolución profesional y espacial entre 1965 y 1970. 


\section{Un análisis de las actividades pied-noir}

Frente a los datos que arroja el padrón de habitantes, hemos podido identificar gracias a nuestras bases de datos, entre finales de los años 50 y los años 70 , incluyendo las personas de Tipo 1, 2 y 3 (b/d) un total de 396 comercios y empresas llevados por pieds-noirs en la ciudad de Alicante. La tabla n. ${ }^{\circ} 4$ los organiza según el tipo de actividad:

\begin{tabular}{|c|c|c|}
\hline Tipo de actividad & Tipo 1-2 & Tipo 3b-3d \\
\hline Alimentación & 12 & 6 \\
\hline Carnicería, charcutería & 7 & 4 \\
\hline Panadería, pastelería & 20 & 2 \\
\hline Bar, cafetería, salón de té & 41 & 22 \\
\hline Bar con recreativos (billares, juegos) & 2 & 0 \\
\hline Club/boîte/whisky/sala de fiestas, discoteca & 14 & 13 \\
\hline Rotisería/ventas de comida/snack & 2 & 2 \\
\hline Bar/restaurante & 13 & 25 \\
\hline Casa de huéspedes/hotel/pensión & 10 & 1 \\
\hline Camping & 1 & 2 \\
\hline Alquiler de caballos & 1 & 0 \\
\hline Barbería/peluquería/instituto de belleza & 16 & 9 \\
\hline Droguería/perfumería/mercería & 7 & 6 \\
\hline Venta de artículos de lujo & 3 & 0 \\
\hline Venta de confección/bisutería/relojería & 9 & 12 \\
\hline Alquiler /venta de electrodomésticos & 2 & 2 \\
\hline Venta de instalaciones para el hogar/bricolaje & 5 & 1 \\
\hline Hogar/objetos de decoración & 3 & 4 \\
\hline Decoración/arquitectura & 1 & 1 \\
\hline Talleres/servicios de reparación y mantenimiento & 9 & 2 \\
\hline Taller mecánico/electrónico & 19 & 5 \\
\hline Pressing/ lavadero & 2 & 2 \\
\hline Venta de discos/libros & 5 & 2 \\
\hline Papelería/fotocopias/estudio de fotos & 0 & 4 \\
\hline Venta/servicios automóvil & 8 & 2 \\
\hline Compañía de taxis & 1 & 0 \\
\hline Embarcaciones deportivas & 1 & 0 \\
\hline
\end{tabular}




\begin{tabular}{|l|c|c|}
\hline Comisionista/representación/ import-export & 7 & 4 \\
\hline Agencia inmobiliaria & 4 & 4 \\
\hline Asesoría/promoción & 2 & 0 \\
\hline Venta de seguros & 3 & 1 \\
\hline Promotor inmobiliario & 1 & 2 \\
\hline Empresa de transportes/mudanza & 3 & 1 \\
\hline Consultorio médico/ servicios de salud & 1 & 4 \\
\hline Escuela/guardería/internado & 4 & 0 \\
\hline Oficinas de periódico & 1 & 0 \\
\hline Servicio de traducciones & 1 & 0 \\
\hline Comercio/empresa no especificada & 10 & 1 \\
\hline TOTAL & 247 & 146 \\
\hline
\end{tabular}

Tabla n. ${ }^{\circ}$ 4: Actividades económicas de las personas de tipo 1-2 y 3 (b, d) en el sector terciario, en la ciudad de Alicante (años 50-70).

Los primeros comercios pieds-noirs que hemos podido identificar abrieron sus puertas desde finales de los años 50. La mayoría eran de tipo tradicional, como servicios de reparación, casas de huéspedes, panaderías, bazares y bares. A partir de los años 1961-1962, empezamos a ver aparecer otro tipo de actividades: talleres de reparación de electrodomésticos, salas de billar y de juegos, cafeterías y restaurantes modernos, salas de fiesta, tiendas de decoración. Los comercios más innovadores acompañaron la transformación de la región como zona turística y la terciarización de la economía.

A partir de esa época proliferaron en la ciudad y en la provincia las tiendas de confección, papelerías, tiendas de música y librerías. También se produjo un desarrollo notable de las agencias inmobiliarias. La presencia de los piedsnoirs en esos sectores se inscribió en una tendencia general. No obstante, un fenómeno les es propio: se trata de la apertura de pastelerías que ofrecían productos franceses y pieds-noirs. Ese tipo de comercio, al igual que las carnicerías que vendían productos típicos de Argelia (como la merguez), respondían a necesidades específicas de la colonia recientemente instalada que introdujo ciertos productos en la región para consumo propio. En cuanto a las personas de tipo 3 (b/d), las tendencias fueron similares entre 1954 y 1962, con una concentración de las actividades en el sector terciario (90\%) y en los dominios citados precedentemente.

Este análisis confirma la contribución de los pieds-noirs al sector terciario alicantino. 
No obstante, a pesar de su preeminencia en las actividades terciarias, los pieds-noirs también trabajaron en el sector secundario y en menor medida, en el sector primario (agricultura, ganadería, pesca).

En el sector secundario, encontramos 64 personas dedicadas a diferentes oficios artesanos en 1965, 82 en 1970. Sin embargo, las actividades industriales aparecen diluidas en los padrones. La consulta de otros documentos nos permitió profundizar y extender nuestro estudio al conjunto de la provincia.

En el sector de la construcción, los pieds-noirs no participaron directamente en la construcción de obras emblemáticas de la época, como la Finca Adoc de Charles Pradel, pero fueron una buena parte de los compradores, sobre todo a partir de mediados de la década de los 60 , cuando fueron mejorando su situación financiera, y nuevas familias llegaron desde Francia con capitales. Las estrechas relaciones de Pradel con la comunidad pied-noir los transformó en portavoces del proyecto en Francia ${ }^{19}$. Por otro lado, la colonización de La Albufereta por parte de los pieds-noirs se realizó de otra manera: a medida que aumentaba su presencia como residentes, se iban convirtiendo en propietarios de numerosos comercios situados en los bajos de las urbanizaciones. Esa zona residencial moderna e innovadora se transformó, así, en un lugar de vacaciones y de vida aún más atractivo.

Cabe añadir que, a lo largo de los años 60 y 70 algunos europeos de Argelia crearon negocios en el sector de la construcción.

De la ciudad a la provincia: el caso de El Campello, Villajoyosa, Jávea, San Vicente del Raspeig y Benidorm

Aunque algunas ciudades pequeñas y pueblos de la provincia contaron con una presencia no desdeñable de europeos de Argelia, particularmente en la Marina Baja y El Alacantí y en zonas turísticas; la actividad pied-noir fue más importante en las ciudades grandes y medianas del litoral como Denia, Benidorm, Santa Pola o Torrevieja.

La imposibilidad de acceder a los archivos de ciertos municipios nos ha conducido a constituir una muestra incompleta, pero que podría ser representativa de la región ${ }^{20}$.

El pequeño grupo de pieds-noirs instalado en Jávea entre 1965 y 1970 se componía esencialmente de jubilados, obreros agrícolas y obreros de la construcción, aunque también encontramos un chófer de taxi (hubo unos

19. Le Courrier du Soleil, n. ${ }^{\circ} 10,28 / 02 / 1966$, p.12. El semanario promocionó los apartamentos de Rocafel S.A.

20. A partir de los archivos locales y provinciales, las colecciones de prensa. 
cuantos en la ciudad de Alicante). En El Campello, los trabajadores agrícolas, albañiles u obreros fueron numerosos, pero también los comerciantes e industriales. Algunos pieds-noirs de El Campello y muchos repatriados de Marruecos trabajaban en esta época en las industrias asociadas a la pesca: el calafateado, la reparación de barcos y de redes. En Villajoyosa, en cambio, a pesar de ser una ciudad de tradición pesquera, encontramos sobre todo comerciantes, empresarios, representantes, artesanos, chóferes y jubilados. Finalmente, en San Vicente del Respeig, residían entre 1965 y 1970, numerosos jubilados de la Argelia francesa, así como obreros (3), artesanos (4), comerciantes (3), industriales (2) y empleados (9).

En cierta medida, podríamos concluir que existía una oposición entre la capital (donde prevalecía el perfil comerciante e industrial) y el interior de la provincia (donde dominarían los trabajos tradicionales en el sector primario, en la industria y los servicios). No obstante, el estudio global de nuestras fuentes nos conduce a matizar esta afirmación, al mostrarnos que la presencia de los pieds-noirs en el sector terciario fue extensible al conjunto de la provincia, en particular en las zonas más turísticas y dinámicas.

Constituidas a partir de fuentes más dispersas y parciales, nuestras bases de datos no nos permiten establecer una periodicidad tan clara de esta implantación como para la ciudad de Alicante. Entre los años 50 y 70, hemos repertoriado en la provincia 174 comercios y empresas de todo tipo, creadas por personas de tipo 1, 2 y 3. Entre ellas, 122 pertenecen a personas de tipo 3, esencialmente b-c, y 53 a personas de tipo 1 y 2 . Estos negocios son, en su mayoría, de turismo, restauración, hostelería y alimentación.

En este recorrido por la provincia de Alicante, la ciudad de Benidorm merece una mención especial. La nueva orientación urbanística y económica impulsada a partir de 1956 en Benidorm por el alcalde Pedro Zaragoza Orts, que persiguió la creación de una ciudad turística y el desarrollo del sector terciario, implicó una ruptura histórica para este tradicional pueblo de pescadores. Desde 1970, el crecimiento de la ciudad se aceleró, gracias al desarrollo de infraestructuras, a las construcciones en altura, a la publicidad difundida en el extranjero. El número de turistas que visitaba la ciudad se multiplicó. Pero ya desde finales de los años 50 se habían desarrollado los primeros lugares de ocio (boîtes, whiskies, salas de fiesta).

En Benidorm, primer feudo pied-noir después de la capital de la provincia, hemos localizado 87 actividades en el sector terciario, gestionadas en esta época por exiliados de Argelia o personas de tipo 3 (b/d). Entre ellos, numerosos clubes, cafeterías, discotecas y whiskies (45) abiertos durante los años 60, algunos célebres como el Jimmy's de la Plaza Triangular, el Esguit «whisky a 
gogo», el Safari en la zona de Fluixa, el Dolmen's de la avenida Gambo, Las Vegas en la periferia de Benidorm (hoy Jaume I y Alfonso Puchades), el Sierra Dorada en el Rincon de Loix, el Cap 3000 en la ruta de Valencia (actual avenida de la Comunidad Valenciana).

En ese mismo periodo, abrieron en Benidorm 42 comercios diversos, esencialmente vinculados con el turismo.

La mayoría de los establecimientos se situaban en la zona de primera expansión de Benidorm: la Playa de Levante, en torno a Plaza Triangular, la Avenida del Mediterráneo, la Avenida de Europa y la calle Gambo, en la zona del Rincón de Loix; aunque hemos localizado actividades situadas en la periferia norte de la ciudad. La Cala, en el extremo occidental de la ciudad, también fue ocupada en la primera mitad de los años 60. En La Cala, Robert Tabarot $^{21}$ abrió junto con René Tarí su primer comercio, una pizzería-whisky, antes de dedicarse al negocio inmobiliario. La zona del Poniente, al oeste de la ciudad fue el límite de la parte urbanizada durante los años 60. Las primeras construcciones fueron realizadas durante este periodo, en torno a la actual Avenida Jaume I, como el Hotel Golden de Pedro Alós.

Si en la ciudad de Alicante los proyectos fueron más modestos, el caso de Benidorm es digno de ser destacado. Un grupo de empresarios presentes en la ciudad desde los años 60, se dedicó a la promoción de negocios ambiciosos: Michel Salvador (Jimmy's, Safari, Dolmen's, Sierra Dorada), Robert Tabarot (Derrick's) ${ }^{22}$, Robert Bataouche (El Papagayo), Vicente Pérez Ivorra (LEsguit, Cafetería Fluixa), Guy Lanuza (El Barrank), o la familia Ballester (construcción). Esas personalidades se asociaron a menudo entre sí, o con otros pieds-noirs o españoles, como Fernand Martínez, Serge Darmanian y Charles Sambeat.

Los proyectos encabezados por esos empresarios acompañaron el crecimiento impresionante de una ciudad que se transformó en pocos años en uno de los principales destinos turísticos de Europa. Lugar de residencia para numerosos pieds-noirs, fue también un polo de atracción para las inversiones de los empresarios residentes en toda la región. La apertura en 1974 del Collège Français de Benidorm, anexo del Liceo de Alicante, a la iniciativa de un grupo

21. Uno de los principales líderes de la comunidad pied-noir, antiguo miembro de la OAS en Argelia e importante empresario en la ciudad de Alicante y en Benidorm.

22. En los años 80 , Tabarot está detrás de la construcción del parque acuático Aqualandia, de terrenos de golf y residencias de lujo, del casino de Villajoyosa y el Palacio de Congresos de Benidorm. 
de padres de alumnos ${ }^{23}$, confirma la presencia de europeos de Argelia en la ciudad y en la zona de La Marina alicantina.

\section{La evolución de las actividades pieds-noirs y la evolución urbana alicantina}

En la ciudad de Alicante, las actividades económicas pieds-noirs también fueron ocupando el espacio de la ciudad, contribuyendo a la visibilización del grupo y a su territorialización. Hemos localizado muchas de estas actividades en las diferentes zonas de la ciudad y de forma cronológica.

En 1962, 18 aperturas de comercios fueron solicitadas por personas de tipo 1 y 2 en el centro de Alicante, los barrios semiperiféricos de San Blas, Florida, Campoamor, los barrios periféricos de Virgen del Remedio y los nuevos barrios del Norte. Se trata de 6 salones de belleza, la tienda de electrodomésticos El hada del hogar de Juana Contreras, la Cafetería Luna de la Rambla y dos comercios relacionados con el mantenimiento del automóvil, sector que se vuelve cada vez más importante.

Los perfiles de tipo 3, siguieron las mismas tendencias. A los comercios tradicionales ( 1 salón de belleza, 1 comercio de venta de productos de cuero) debemos añadir un camping en La Albufereta, que responde al aumento de visitantes en la región.

Entre 1963 y los años 70, identificamos 105 aperturas de comercios o empresas solicitadas por personas de tipo 1 y 2 , sobre todo en los años 1963 y 1965. Esta cronología debe ser matizada, ya que las demandas de apertura se realizaron con frecuencia de forma tardía, aunque los negocios ya estuvieran en funcionamiento.

Durante esos años, se diversificaron las actividades y empezó el auge de las inmobiliarias y de las oficinas de seguros. Varias empresas de este tipo fueron creadas por pieds-noirs (dos de ellas son la sede alicantina de agencias nacionales o internacionales). También se crearon una sociedad económica y turística, oficinas de representación y venta, empresas de transporte y de mudanzas. Muchas de esas iniciativas fueron lideradas por personalidades como Fernand Feral ${ }^{24}$.

Entre las creaciones de comercios, 78 están en relación con la alimentación, el ocio, la moda o el hogar. Numerosos establecimientos que serán

23. Note sur le Lycée Français d'Alicante et établissements d'Espagne liés à la MLF de novembre 1977, Centres d'enseignement. Fonds des Services culturels de l'Ambassade à Madrid (398PO-69). CADN-AMAE.

24. Empresario pied-noir, fue uno de los fundadores de la NEF y su director durante muchos años. 
emblemáticos abrieron sus puertas en esa época. Por ejemplo, la Cafetería Biarritz, de los hermanos García, y la Cafetería Blanco y Negro de Jean Escamilla, en La Albufereta; la Cafetería Imperial de Philippe Anziani, el Totem Whisky de Jean-Pierre Conesa, el Whisky a chorro de André Maciá, en el centro de Alicante. Este periodo coincide asimismo con la apertura de los primeros pressings, como el Royal Pressing de Arqueros, Ferrer y González. En esa época abrieron sus puertas 18 talleres de reparación, montaje o mantenimiento automotor y de electrodomésticos. Antoine Fuentes inauguró en 1964 su comercio de tapicería Las Tres Fuentes, en un primer momento en la ciudad, más tarde en un local en Avenida de Denia (Vistahermosa), donde, desde 1965, también se vendieron muebles.

A partir de 1963, hubo una tendencia a instalarse en nuevas zonas, como La Albufereta, Vistahermosa, Playa San Juan o la calle Virgen del Socorro (Raval Roig), adaptándose al lugar de residencia de las familias. Entre 1950 y 1970, hemos localizado 3 aperturas en la zona de Vistahermosa (en relación con las actividades escolares), 13 en La Albufereta, 6 en la Playa San Juan y 1 en Virgen del Socorro, pertenecientes a propietarios de tipo 1 y 2 . Esos comercios y empresas, esencialmente de restauración, se situaron, en general, en los locales de los edificios residenciales (Gafner, San Jorge, Paraíso, Rocamar en Albufereta; Ulises, Flamingo o Saint Trop en Playa San Juan) donde vivían muchos miembros de la colonia francesa alicantina.

En cuanto a las personas de tipo 3, hemos localizado 33 negocios en La Albufereta (situados en las mismas zonas de apartamentos o en chalés individuales) 5 en Virgen del Socorro, 16 en Playa San Juan (zona de primera construcción y Cabo de Huertas) y 1 en Vistahermosa, Avenida de Denia. En la mayoría de los casos se trata de establecimientos de restauración, hotelería o lugares de ocio abiertos entre la segunda mitad de los años 60 y principio de los años 70 .

El aporte de los pieds-noirs a la nueva configuración de la economía local fue, por lo tanto, muy importante, no sólo por el tipo de actividades que desempeñaron, sino también porque su implantación espacial fue el reflejo del crecimiento urbano de la época y atrajo a nuevas poblaciones extranjeras.

Los planos que presentamos a continuación reproducen la proyección en el espacio de diferentes tipos de comercios y empresas creados por esta población en el periodo estudiado. Los planos 1 a 3, que corresponden con el periodo 1962-1970, ponen de relieve la conquista de los nuevos barrios por los pieds-noirs, retomando los elementos de nuestra nomenclatura (tipo 1, 2, 3 b/d). Los planos 4, 5 y 6 se focalizan en los barrios en los que esa conquista ha 
sido más fuerte, es decir, la zona de La Albufereta y San Juan (4) pero también el centro de la ciudad, esencialmente La Rambla y la Explanada (5) ${ }^{25}$. Vemos que las iniciativas empresariales y comerciales pieds-noirs se concentraron en los barrios emblemáticos del crecimiento económico y demográfico y en ciertas zonas del corazón de la ciudad. En el centro de Alicante, las grandes cafeterías y los bares más modernos se instalaron en la Explanada o La Rambla, y en las calles laterales. En esas dos grandes arterias, se implantaron asimismo oficinas de seguros, agencias inmobiliarias, servicios financieros y asesorías. Otros negocios pieds-noirs se situaron en la zona del Centro-Ensanche, Avenida Alfonso el Sabio, o en los barrios del norte, avenidas Novelda, Alcoy y Jijona. Esos barrios, con una población menos densa, acogieron talleres mecánicos, parkings o empresas ligadas a la industria o al comercio mayorista.

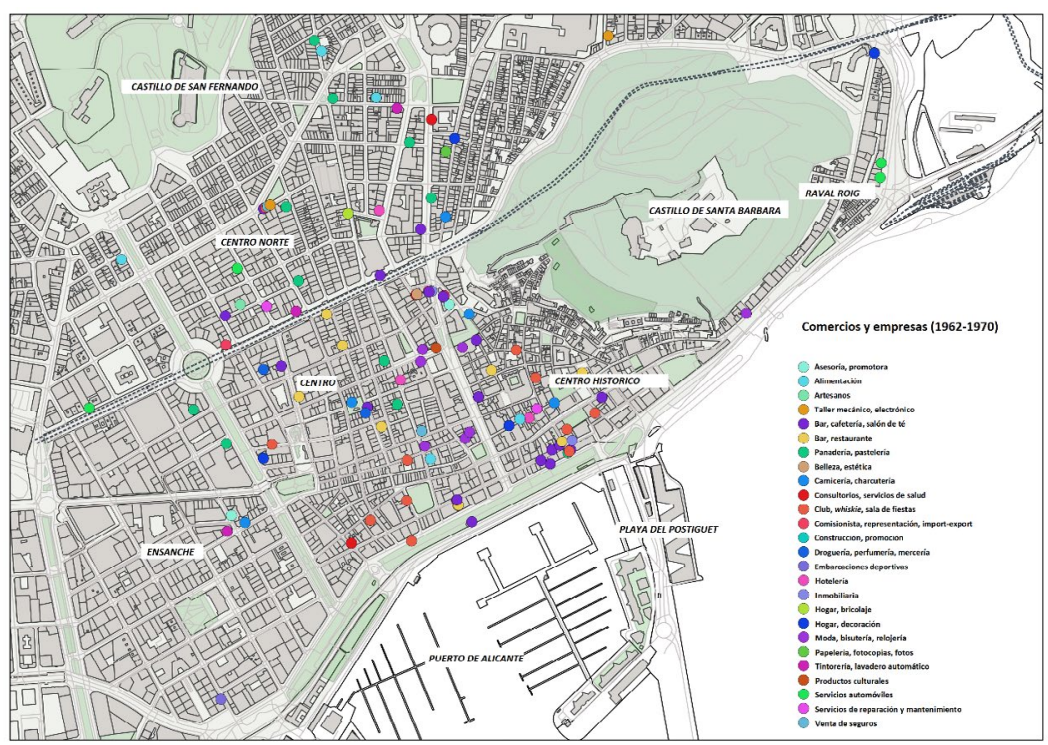

Plano n. ${ }^{\circ}$ 1: Comercios y empresas entre 1962 y 1970, centro de Alicante y Raval Roig. Elaboración de la autora y de Marie Clap. Fuente: AMA.

25. Una centena de comercios que hemos presentado en nuestro estudio no figuran en los planos, por falta de datos precisos para localizarlos, pero refuerzan las tendencias representadas. 


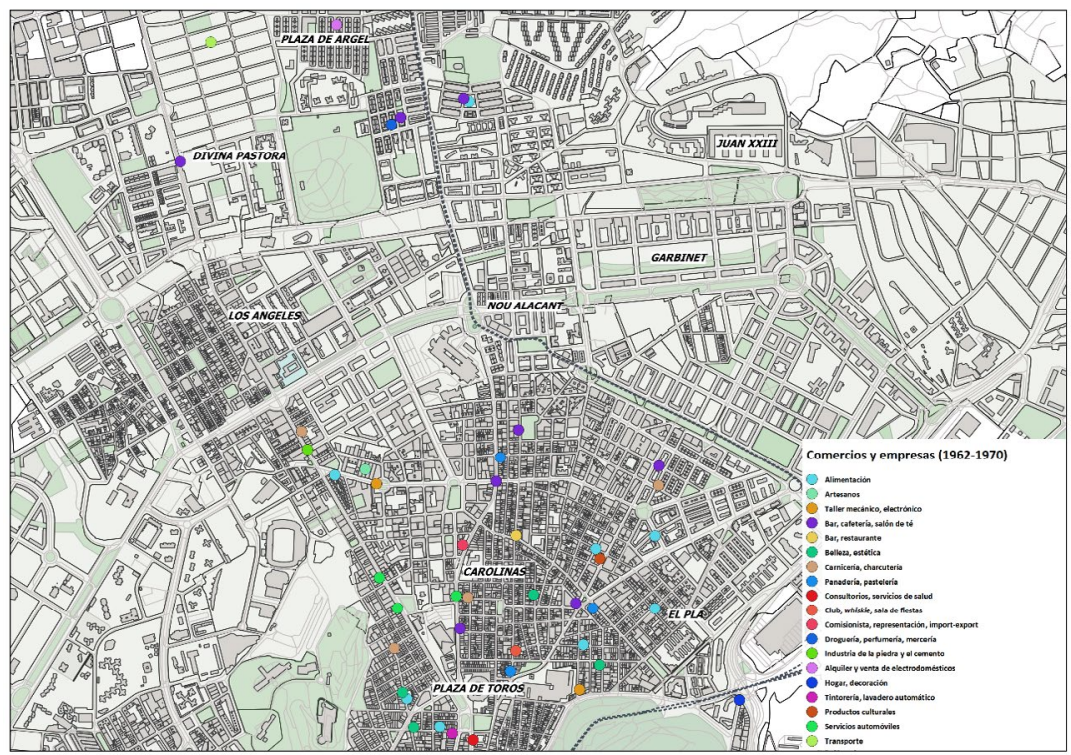

Plano n. ${ }^{\circ}$ 2: Comercios y empresas entre 1962 y 1970, barrios periféricos y semiperiféricos del norte de Alicante. Elaboración de la autora y de Marie Clap. Fuente : AMA.

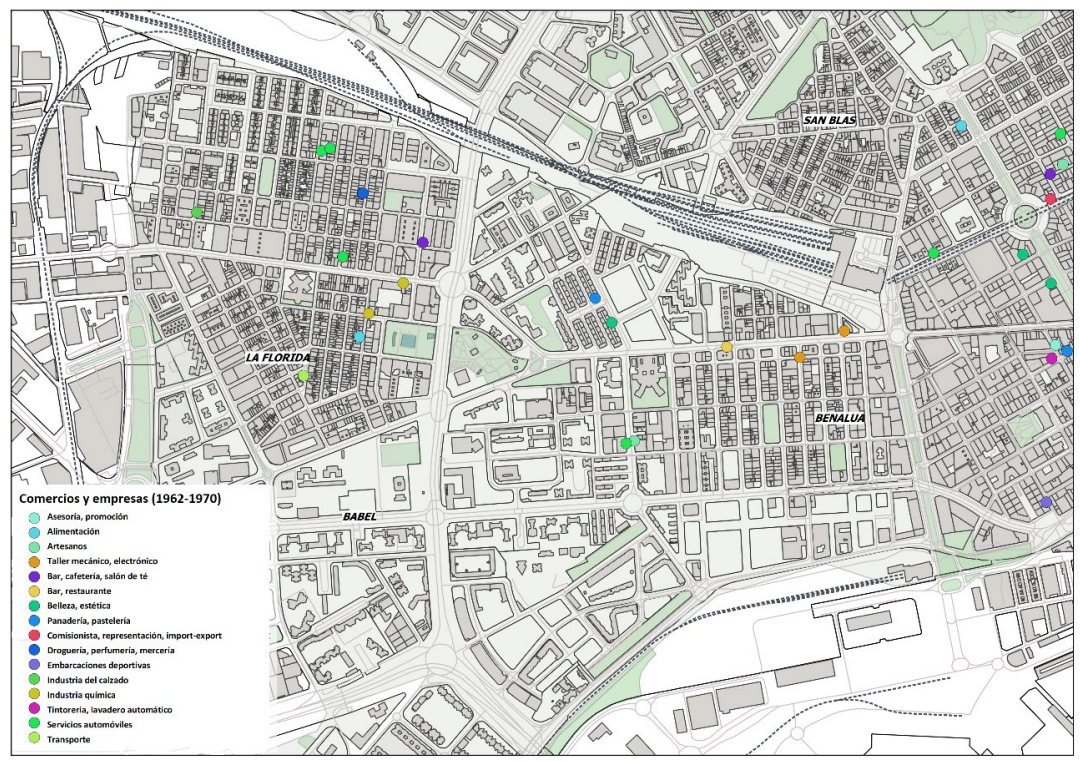

Plano n. ${ }^{\circ}$ 3: Comercios y empresas entre 1962 y 1970, barrios semiperiféricos del este de Alicante. Elaboración de la autora y de Marie Clap. Fuente : AMA. 


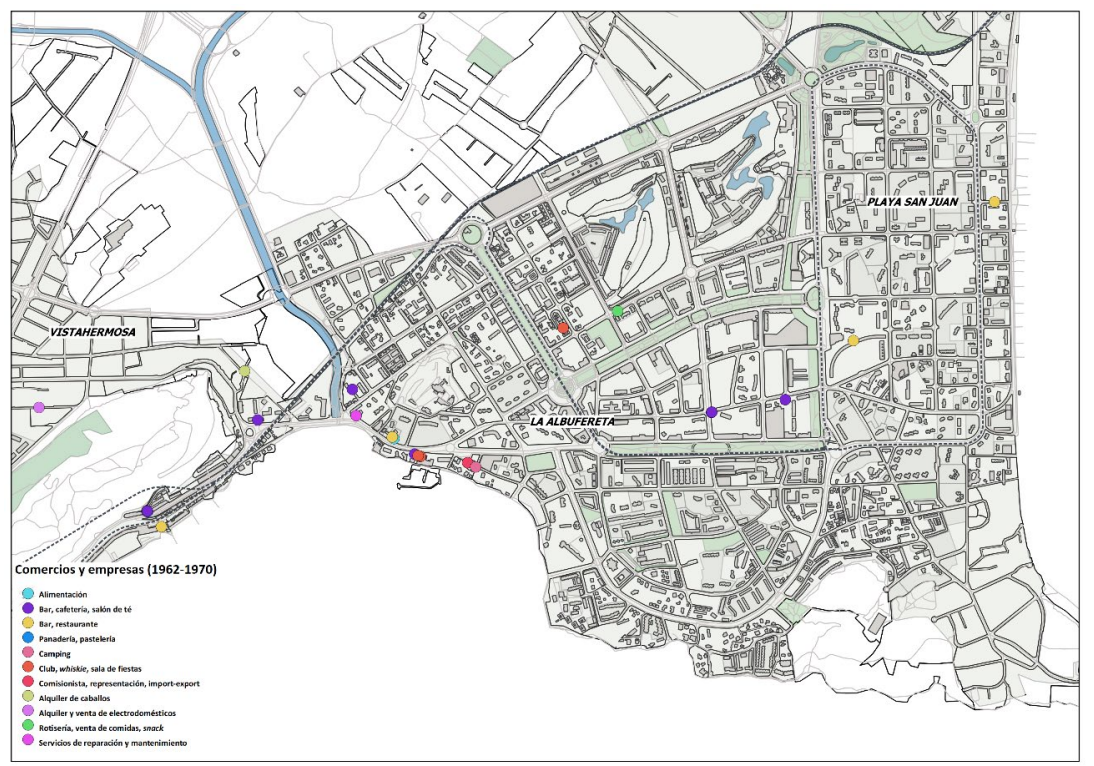

Plano n. ${ }^{\circ}$ 4: Comercios y empresas entre 1962 y 1970, en las zonas costeras del este de Alicante. Elaboración de la autora y de Marie Clap. Fuente: AMA.

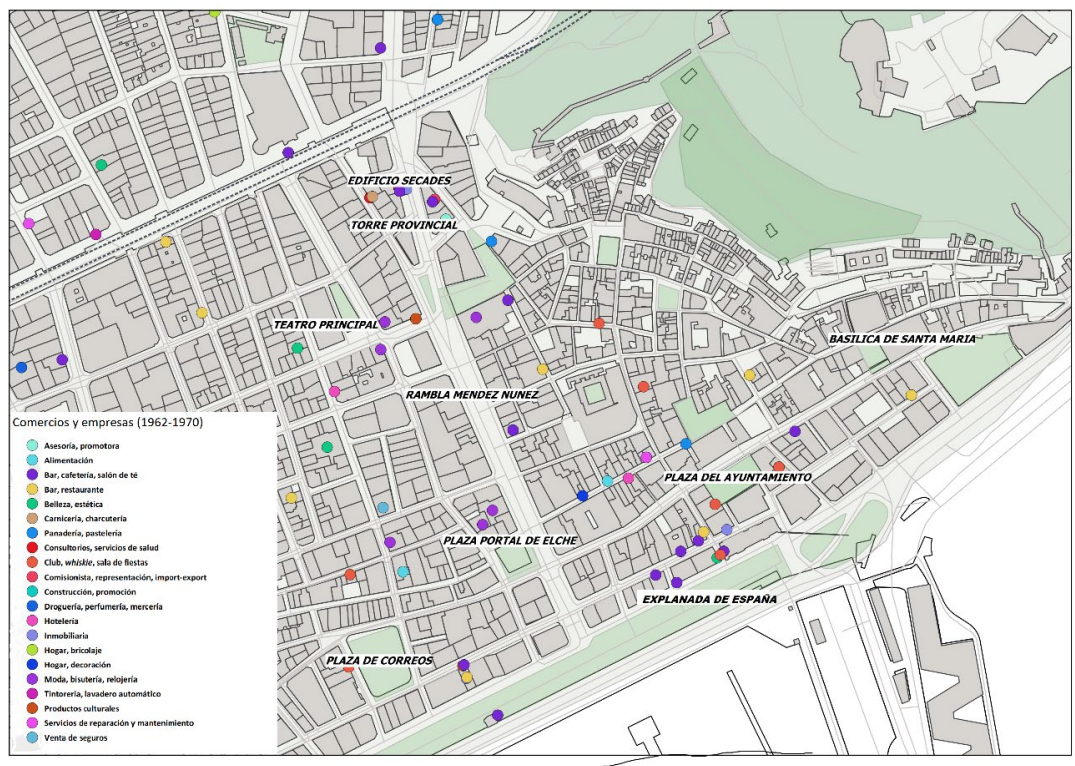

Plano n. ${ }^{\circ}$ 5: Comercios y empresas entre 1962 y 1970, en La Rambla, La Explanada y calles próximas. Elaboración de la autora y de Marie Clap. Fuente: AMA. 


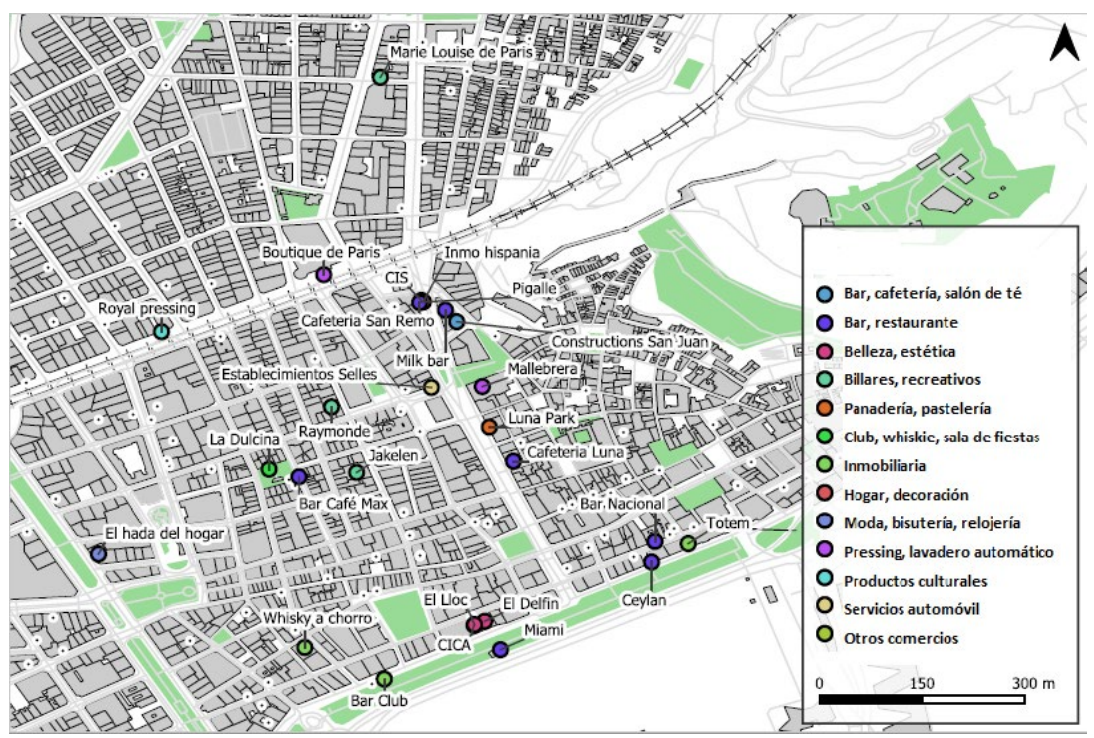

Plano ${ }^{\circ}{ }^{\circ}$ 6: Algunos comercios y empresas pieds-noirs destacados del centro de Alicante. (años 60 y 70). Elaboración de la autora y de Marie Clap. Fuente: AMA.

\section{El impacto social de los pieds-noirs a través de la apertura de comercios}

Los comercios y empresas pieds-noirs acompañaron el ritmo de la transformación de los modos de vida y de consumo en le España de los años 60, al trasponer a la región de Alicante un savoir-faire importado con el éxodo. Promovieron lugares de ocio, desarrollaron el sector del electrodoméstico, de los equipamientos para el hogar, la moda prêt à porter e introdujeron servicios y productos vinculados a una nueva estética, a una nueva forma de vivir (discos, libros, tocadiscos, transistores). Esas dinámicas que ya estaban bien implantadas en Argelia, pero también en Francia y en otros países occidentales, llegaron a España por intermedio de los extranjeros y, a Alicante, particularmente de los pieds-noirs.

Antes de la llegada masiva de los exiliados de Argelia, algunos empresarios locales de la cultura habían puesto en marcha cines y salas de fiestas como El Gallo Rojo en El Campello. El movimiento de modernización había comenzado antes de 1962, pero los pieds-noirs contribuyeron a intensificarlo y acelerarlo. El sector de la restauración y del ocio ofrece un buen ejemplo, con la trasplantación de nuevos conceptos que correspondían a fórmulas que ya existían en la Argelia francesa: whiskies, clubs, snack-bars. En torno a los años 70 , los whiskies y clubs fueron perdiendo progresivamente terreno frente a las discotecas, a menudo alejadas del centro de las ciudades, como Playboy, de los hermanos García en La Albufereta que, al ampliarse, se trasladó. 
La influencia de los pieds-noirs en el comercio tradicional también fue importante. Los negocios de alimentación donde se vendía pan y bollería se transformaron poco a poco en panaderías-pastelerías modernas con servicio de cafetería. Es el caso del Milkbar de la familia Espí. Estratégicamente situado en La Rambla desde 1965, el establecimiento ofrecía pastelería francesa, helados y bebidas, y supo atraer a la juventud local. Otros comercios como las rotiserías o los almacenes evolucionaron hacia el autoservicio, antecedente del supermercado. Los bazares tradicionales fueron remplazados por tiendas que proponían productos adaptados a las nuevas viviendas, mejor equipadas, y muebles de moda. Por último, las pensiones típicas fueron remplazadas por hoteles y apartamentos de vacaciones.

El aspecto estético de estos nuevos comercios también contribuyó a singularizar los lugares y productos pieds-noirs a ojos de la población alicantina, ya que las cafeterías y bares del centro estaban decorados con cuidado y de forma original. Las terrazas de estilo parisino se desarrollaron en toda la región. Muchos bares, cafeterías y clubs solicitaron autorizaciones para instalar tocadiscos y rocolas, que fueron ocupando progresivamente el lugar de la música en directo. Los establecimientos se fueron equipando asimismo de máquinas de juegos y billares ${ }^{26}$.

El estilo decorativo llamativo se puso de moda en toda la costa. El restaurante El Ranchito Veracruz de El Campello y el Grill Room Carol de Jean Mulero en Torrevieja, fueron diseñados por el decorador pied-noir Marcel Quiles. La discoteca Cap 3000 de Benidorm, creada en 1969, tenía un diseño muy innovador: la forma de un ovni y una cabina de disc-jockey con forma de helicóptero. El Sierra Dorada de Michel Salvador, también en Benidorm, estaba decorado con el estilo de una hacienda mexicana ${ }^{27}$. El Blanco y Negro de Escamilla, situado en La Albufereta, primero restaurante y luego sala de baile al aire libre, poseía un salón de invierno interior decorado con pieles de animales salvajes. El periódico pied-noir Le Courrier du Soleil se ocupó de poner en valor esas iniciativas tan «en boga». La publicación anunciaba en 1966 que el salón de belleza Jakelen, de la familia Sempere y situado en la calle Castaños, había sido decorado por Gastón Castelló ${ }^{28}$ y que su cuadro L'arc de triomphe adornaba las paredes del local2 ${ }^{29}$.

26. Varios documentos (1962-1967). Aperturas (1915). AMA.

27. Le Courrier du Soleil, n. ${ }^{\circ} 2,31 / 12 / 1965 ;$ n. ${ }^{\circ} 4,15 / 01 / 1966$.

28. El pintor alicantino Gastón Castelló, de padre nacido en Argelia, había vivido en Francia y en el Norte de África durante algunos años.

29. Le Courrier du Soleil, n. ${ }^{\circ} 4,15 / 01 / 1966$. 
El exotismo de los negocios pieds-noirs residió más en la explotación de la imagen francesa que norteafricana. Los peluqueros y barberos tradicionales se convirtieron en salones de belleza unisex, y centros de estética «a la francesa». Los salones Marie Louise de Paris, de Lucien Camo, Karine de Paris de Charlotte Tourenc, o el ya citado Jakelen, los tres abiertos en 1960 y situados en el centro o a proximidad, reivindicaban la elegancia parisina. Las tiendas de moda, bisuterías y perfumerías siguieron la misma estrategia, al vender productos y marcas de importación, sobre todo franceses, como el joyero Mallebrera, situado en la Calle Bailén y, desde 1963, en la Rambla, o la boutique Marie-France de Got y Giner, abierta en 1964 en una calle paralela a La Rambla. Desde finales de los años 60 y a principio de los años 70, se inauguraron en el centro de Alicante nuevas tiendas de confección y venta de ropa: Boutique de Paris, Evamag, Shopping. Poco a poco, el prêt à porter fue desplazando la tradicional confección a medida.

Ciertas empresas se dedicaron a la venta y representación de productos y marcas francesas considerados como de lujo o de calidad reconocida. Durante los años 60 y 70, Navarro vendía sanitarios de la marca Porcher, Náutica Boronad proponía motores de barco de marca Baudouin, y varios comercios pieds-noirs de la ciudad vendían los tocadiscos franceses Sonexco. La empresa de somieres y colchones Manufacturas Winter ofrecía mercancías de fabricación francesa, y la sociedad Construcciones San Juan puso de relieve la utilización de técnicas y materiales franceses para la construcción de sus inmuebles.

Por último, los pieds-noirs contribuyeron a difundir en la región productos y usos que antes eran desconocidos o poco comunes. Recordemos el auge de los pressings, las tiendas de discos y los servicios para el automóvil. En el primer caso, tras el éxito del Royal Pressing en la Avenida Alfonso el Sabio, otros tintoreros abrieron sus puertas en toda la ciudad y en La Albufereta en los años 60 y 70: el Ideal Pressing de Selva, el pressing Volvoreta de Amoros en la Finca Gafner, etc. Pressings y lavaderos automáticos fueron también negocios habituales entre los pieds-noirs instalados en Francia, lo que puede explicarse por el desarrollo de ese tipo de actividad en Argelia en los años 60 o por un efecto de imitación del grupo a ambos lados de la frontera.

A pesar de la censura franquista, el gusto por una nueva música se desarrolló entre la juventud española de los años 60. Ese movimiento, asociado a la revolución tecnológica de los aparatos domésticos comercializados a precios asequibles, explica el auge de las tiendas de discos. Además de la venta de aparatos para particulares o de uso público, la venta de discos se desarrolló. En los años 60, Raymond Selles inauguró su establecimiento de discos, tocadiscos y otros electrodomésticos en la calle Duque de Zaragoza, justo al lado de La 
Rambla. Un segundo establecimiento del mismo dueño abrió sus puertas en otra zona comercial del centro (calle Ángel Lozano) ${ }^{30}$.

Los servicios relacionados con el automóvil constituyeron, finalmente, uno de los sectores representativos de los cambios sociales que estaba sufriendo la sociedad alicantina en los años 60. A principios de esa década, el uso del vehículo particular era muy escaso en la región. Muchos de los pieds-noirs que se instalaron en la ciudad llegaron, sin embargo, con sus automóviles. Pocos años después de su instalación en Alicante, se hablaba de ellos significativamente como «Los de los mil coches» (Cosme, 2015). Fue por eso por lo que fueron precursores en los negocios vinculados con el mundo del automóvil, poco antes de su auge en la provincia, impulsado por las políticas de transporte locales y por la mejora del nivel de vida de las familias españolas, permitiendo la adquisición de un coche. Entre los años 60 y 70, numerosos establecimientos vinculados a ese sector fueron creados por pieds-noirs: talleres para el mantenimiento, garajes, tiendas de suministros de material y de equipamiento, carrocería, pintura, estaciones de lavado y engrasado, estaciones de servicio y gasolineras. Se multiplicaron por toda la ciudad los talleres de tapicería para coches, las empresas de alquiler de automóviles, los concesionarios, como Automóviles Paris, fundado en los años 70 en el barrio de El Pla.

No se trataba únicamente de la introducción de nuevas actividades y productos de consumo, sino de «modos de hacer» innovadores, particularmente visibles en los sectores inmobiliario, de los seguros, de la asesoría a las empresas, de la representación de marcas de standing. Esos sectores habían surgido para responder a nuevas necesidades: asegurar la vivienda o el automóvil, invertir para poder disponer de un capital o multiplicarlo, el recurso al crédito como vía de ascensión. Su desarrollo implicó la introducción de nuevas aptitudes vinculadas con el marketing y las técnicas comerciales modernas, que los pieds-noirs contribuyeron a implantar en la región de Alicante. Las prácticas como la venta puerta a puerta, la compra en cuotas y los nuevos modos de inversión, especialmente en el sector inmobiliario, son ejemplos.

Las formas de solidaridad que existieron en el seno del grupo hicieron posible la success story de los pieds-noirs de Alicante. Por un lado, éstos se asociaron frecuentemente entre ellos para abrir una empresa o comercio. Por otro, la amistad con españoles, que en algunos casos actuaron como testaferros, en otros como socios, facilitó los proyectos colectivos y los traspasos. En 1961, Max Paul Varo abrió en el número 34 de La Rambla, su establecimiento de billares y juegos Luna Park. Su negocio se situaba en los locales de la tradicional

30. También librerías como La tour d'Occident en la Finca Gafner (1968).

Pasado y Memoria. Revista de Historia Contemporánea, 24, 2022, pp. 295-321 
mercería Soriano con cuyos dueños Varo compartía una relación de amistad. Cabe mencionar, por otro lado, que ciertas actividades abiertas en los primeros años fueron traspasadas más tarde a otros miembros de la comunidad.

Más allá de los negocios que se realizaron en la esfera familiar, especialmente en el pequeño comercio, las inversiones colectivas fueron frecuentes, ya que la mayoría de los pieds-noirs no disponían de grandes sumas de dinero. Cuando una familia abandonaba la provincia o decidía dedicarse a otra actividad, esas empresas solían cederse a otros europeos de Argelia. Esa renovación al interior de la comunidad permitió que la mayoría de los comercios persistieran en el tiempo, al menos más allá de los años 60 , tras haber atravesado numerosas transformaciones. Esta forma de empresariado étnico (Ma Mung, 1996) implicaba asimismo a los empleados, ya que muchas empresas pieds-noirs contrataban repatriados de Argelia. Por otra parte, el carácter étnico de esos negocios residía en su clientela y en los productos que ofrecían (franceses y típicos del Norte de África como el couscous), generalmente destinados a un público pied-noir, incluso si con el tiempo fueron ganando una importante clientela española.

Esta estrategia de alianzas y la fidelidad de los clientes garantizaron el éxito de muchos comercios, permitiendo a las tiendas más modestas sobrevivir a pesar de la situación financiera precaria de muchas de ellas.

Es indudable que los pieds-noirs tuvieron un papel pionero en el desarrollo de la economía y del turismo alicantinos desde finales de los años 50 . Su participación en el crecimiento económico, en particular en los sectores más visibles y en pleno auge en esa época (el comercio, la restauración, la hostelería) no fue un mito, sino una realidad que las fuentes confirman.

Su dinamismo puede interpretarse como una transposición de experiencias y aptitudes adquiridas en Argelia. El carácter innovador de los pieds-noirs se explicaría, entonces, por su estatus de migrantes de la descolonización. El savoir-faire acumulado antes del éxodo habría sido transferido a un país atrasado en términos de desarrollo económico. En ese sentido, España habría sido, contrariamente a la metrópoli, un país en el que el campo de posibilidades habría sido más amplio.

Más allá de las facilidades y ayudas recibidas otros elementos habrían reforzado el carácter emprendedor de los pieds-noirs. El primero, sería que los ahorros traídos de Argelia tuvieron mucho más valor en España y les ofrecieron una posibilidad de invertir de la que carecían muchos alicantinos. No hay que olvidar tampoco que, debido a su situación de exilio, los pieds-noirs se encontraron frente a la urgencia de tener que emprender para poder vivir. Por último, hay que señalar que muchos de ellos no hablaban español ni valenciano en 1962, por lo que el recurso al autoempleo fue una solución. 
El éxito de los empresarios pieds-noirs fue también el resultado de una sutil combinación entre nuevas prácticas y modos de hacer las cosas y la movilización de redes de tipo étnicas relacionadas con la historia del grupo.

La presencia de esta comunidad en Alicante no sólo contribuyó al desarrollo económico de la región en los años 60 y 70, traduciéndose en el territorio. El impacto de las iniciativas empresariales pieds-noirs trascenderá en el tiempo a través de los nuevos negocios de los años 80 y 90, de las movilidades interfronterizas y de la multiplicación del número de jubilados que practican un turismo residencial en la región (Sempere, Domínguez, 2021). A pesar de la desaparición de los primeros comercios, suplantados por iniciativas más modernas, y de la pérdida de visibilidad pied-noir en el espacio frente a la presencia de otras comunidades inmigradas, éstos han dejado una herencia que se ha transformado y se perpetúa a través de las nuevas generaciones.

\section{Bibliografía}

DOMÍNGUEZ VILLAVERDE, Mariana (2019). Ser y Estar. Les Pieds-Noirs d'Alicante et de sa région, d’une rive à l'autre de la Méditerranée (1962-années 2000) [tesis doctoral]. Universidad de Alicante, Aix-Marseille université.

COSME, Stéphane. (2015). Alicante, une alternative entre l'Espagne et la France [Audio podcast]. Recuperado de htpp://www.rts.ch.

MA MUNG Emmanuel (1996). Entreprise économique et appartenance ethnique. Revue européenne des migrations internationales.12. 2. 211-233.

MARIMÓN RIUTORT, Antoni (2013). El sur también existe. Las relaciones migratorias entre las islas Baleares y la Argelia francesa (1830-1962). Pasado y memoria. 12. 55-77.

MORENO SÁEZ, Francisco; MARTÍNEZ LEAL, Juan (2018). Dictadura, desarrollismo y cultura. La provincia de Alicante en los sesenta. Alicante: Instituto alicantino de cultura Juan Gil-Albert.

PALACIO, Léo (1968). Les Pieds-Noirs dans le monde. Paris : John Didier.

SEVA LLINARES, Antoni (1968). Alacant. 30.000 pieds-noirs. Barcelona : Edicions 62.

SEMPERE SOUVANNAVONG, Juan David (1998). Los pieds noirs d'Alicante: Las migraciones inducidas por la descolonización. Alicante: Universidad de Alicante. SEMPERE SOUVANNAVONG, Juan David (2001). Les pieds-noirs à Alicante. Revue européenne de migrations internationales. 17. 3.173-198.

SEMPERE SOUVANNAVONG, Juan David; DOMINGUEZ VILLAVERDE, Mariana (2021). La mobilité des Pieds-noirs entre l'Espagne et la France depuis 1962. Rives Méditerranéennes. 62. 175-192. 